\title{
Diversity analysis of maize inbred lines using DIVA-GIS under temperate ecologies
}

\author{
Z. A. Dar, A. A. Lone, N. Sunil", N. Sivaraj ${ }^{* *}$, G. Zafar, M. I. Makdoomi, Asima Gazal, B. \\ A. Elahi, G Ali, M. Habib, and M. A.Wani \\ Dryland Agriculture Research Station, Budgam, SKUAST-K-190025 (J\&K), INDIA \\ "Winter Nursery Centre, ICAR- IIMR, Rajendranagar, Hyderabad-500030, INDIA \\ ${ }^{* *}$ National Bureau of Plant Genetic Resources, Regional Station, Rajendranagar, Hyderabad- 500030, INDIA \\ *Corresponding author. E-mail: zahoorpbg@gmail.com
}

Received: December 21, 2015; Revised received: June 09, 2016; Accepted: August 14, 2016

\begin{abstract}
The vagaries of Climate Change variability need to be addressed and as climatic conditions change at particular experimental sites and maize producing regions, mega-environment assignments will need to be reassessed to guide breeders to appropriate new germplasm and target environments. The development of improved germplasm to meet the needs of future generations in light of climate change and population growth is of the upmost importance. Evaluation of the inbred lines from diverse ecosystems would be effective for production of lines with resilience towards climate variability. Hence, with this objective diverse set of inbred lines sourced from all over India were characterized and were evaluated with DIVA-GIS for diversity analysis of maize inbred lines. Grid maps generated for these maize inbred lines for eleven quantitative traits indicated that these lines can be sourced from North and South India. High Shannon diversity index with maximum range of 2.17-3.0, 2.25-3.0, 2.36-3.0, 2.4-4.0, 2.03.0, and 2.2-3.0 were recorded for the traits viz; plant height, ear height, grain weight, grain yield, kernel row and protein content respectively indicating the high response of these traits to ecosystem. However, inbred lines were found to be diverse for all the traits except for ears plant ${ }^{-1}$ (EPP) and they have been sourced from Northern and Southern parts of India while for EPP recorded less diversity index range of 0.4-1.0 indicating source from South India. Interestingly, less diverse inbred lines for all the eleven quantitative traits have been sourced from Indogangetic plains as indicated in diversity grid maps. Maximum diversity indices were recorded for anthesis silking interval (ASI), days to silking, days to tasseling, which are in the range of $0.97-2.0,1.528-2.0,1.516-2.0$ and 1.528 2.0 respectively. Hence, DIVA-GIS enabled identification of diverse sources from varied ecosystems which can be used for developing improved lines/ cultivars with greater resilience towards climate change.
\end{abstract}

Keywords : Diversity, DIVA-GIS, Grid maps, Maize, Shannon diversity index

\section{INTRODUCTION}

Maize (Zea mays L.) is one of the most important cereal crops globally after wheat and rice and holds a unique position in world agriculture as food, feed and source of diverse industrially important products. It is grown under wide range of climatic conditions, mostly in warmer parts of the temperate region and areas of humid sub-tropical climate. In India, maize has seen steady increase in area and production since 1950 and it occupies an important place as it is used for food, feed and industrial utilization. Maize productivity has been increasing steadily and has recorded impressive growth rate in the last decade in country as a whole, because of adoption of Single Cross Hybrid technology. In Jammu and Kashmir State of India, Maize is the major crop grown over an area of 315.8 thousand hectares with a production of 633.2 thousand tones and a productivity of 20.04 Qtls per hectare. Maize is grown in the state during kharief (rainy) season and about $85 \%$ of the cropped area is rainfed. The average yield levels of this crop have also nearly doubled in the last decade. This increase in yield has been mainly achieved by increase in the area under high yielding varieties mostly single cross hybrid technology and adaptation of recommended technologies developed by Sher-e-Kashmir University of Agriculture Sciences and Technology of Kashmir (SKUAST-Kashmir).

However, the genetic potential of the improved genotypes is at least three times of the present average of the state (Anonymous, 2015). Major constraint for low productivity in Kashmir province is the predominance of landraces adapted to local environmental conditions other being non-availability of vital inputs, in accessibility, scattered and small land holding and cultivation of maize over a wide range of environmental conditions ranging from approximately $1550 \mathrm{~m}$ to above 2,600 metres above mean sea level (m.a.m.s.l) mostly under rainfed environments (Anonymous, 2015). Although Sher-e-Kashmir University of Agriculture Sciences and Technology has developed technologies (viz. 9 Composites and Two Single Cross Hybrids) in the last five years. However, development of adapted com- 
posites/hybrids for these environmental conditions with diverse eco-geographic and environmental conditions is a challenge and a continual activity. Also, the vagaries of climate change/ variability needs to be addressed and as climatic conditions change at particular experimental sites and maize producing regions, megaenvironment assignments will need to be re-assessed to guide breeders to appropriate new germplasm and target environments (Cairns et al., 2012). The development of improved germplasm to meet the needs of future generations in light of climate change and population growth is of the upmost importance (Easterling et al., 2007). Evaluation of the inbred lines from diverse ecosystems might be good source for productive lines with better adaptation to the climate variability. With this in view diverse set of inbred lines sourced from all over India were characterized and evaluated and an attempt has been made to use the DIVA-GIS for the diversity analysis of inbred lines of maize that were characterized and evaluated under local conditions.

\section{MATERIALS AND METHODS}

The present study was conducted on a diverse set of seventy eight inbred lines of maize for three years during 2012-14 at Dryland Agriculture Research Station having coordinates of $74^{\circ} 48^{\prime}$ and $34^{\circ} 3^{\prime}$ and an elevation of 1560 metres above mean sea level (m.a.m.s.l). These lines were both indigenous developed in the Research Station programme as well as lines procured from various sources like Indian Institute of Maize Research, New Delhi, Haryana Agriculture University, Hissar, International Maize and Wheat Improvement Center (CIMMYT), Mexico and others. The procured lines were subjected to stringent selfing and selection for their local adaptive traits for four seasons. These inbred lines were planted in three replications and recommended package of practice was adopted in terms of plant geometry, nutrient inputs and management practices. The maize growing cropping systems of a region are decided by and large, by a number of soil and climatic parameters which determine overall agroecological setting for nourishment and appropriateness of a maize crop. Nevertheless, at the farmer's level, potential productivity and monetary benefits act as guiding principles while opting for a particular crop/ cropping system. Characterized by mountainous and undulating terrain, the state of Jammu and Kashmir has micro-level variations in the agro-climatic conditions. Consequently, the cropping patterns and crop combinations differ significantly at the macro and micro levels. Despite the fact that the agro-climatic variations supported different types of cropping patterns in the state, however, it was the availability or unavailability of irrigation facilities which played a key role in determining the cropping structure in the state. Not surprisingly, therefore, the cropping pattern of the state had been dominated by paddy (the staple food of the ma- jority of the people) in those areas which had adequate irrigation facilities and dominated by maize in the rainfed areas. The peculiar physical character and climate has from times past been a serious handicap to intensive farming and diversification of crops in the valley. As the land remained under snow for 4-5 months a year, therefore, Rice and Maize are the main Kharief crops of the valley. Recent climatic pattern of the valley has witnessed more of dry spells during major maize growing season particularly during early juvenile and pre flowering phase. Genotypes of diverse origins with inbuilt tolerance withstanding various climatic challenges are being channeled in the core research programmes to end up with promising results. DIVA-GIS is a recently updated technology that supports the analysis of exploration, gene bank and herbarium databases to elucidate genetic, ecological and geographic patterns in the distribution of crops and wild species (Hijmans et al., 2001). DIVA-GIS version 7.5 , free downloadable software was used for mapping diversity and statistical analyses of select quantitative traits of maize inbred lines viz., plant height, days to 50 $\%$ silking, days to $50 \%$ tasseling, days to maturity, ASI, ear height, EPP, grain weight, grain yield, Kernel row and protein content recorded on maize inbred lines which were sourced from various agro-ecological regions of India. The geographical coordinates (latitude and longitude) of the source sites of maize inbred lines were assigned using Google Earth and DIVA-GIS. The inbred lines source sites are mapped using DIVA-GIS (Fig. 1). The mapped points were analyzed with the software in an effort to know the spatial distribution and assessment of variability for each of the aforesaid plant traits recorded. Point-to-grid option using circular neighborhood method on the "Analysis Menu" was used to get "grids" over the points of maize inbred lines sourced. The output variable Diversity was selected for getting the output files. Under Diversity option Shannon diversity index was picked. From this output grid maps, the diversity patterns for all the eleven quantitative traits studied on maize inbred lines were generated.

\section{RESULTS AND DISCUSSION}

All the maize inbred lines showed good expression under the new production ecology viz. temperate conditions of the Kashmir valley. The days to tasseling ranged from 73-84 days, days to silking ranged from 78-90 days with a ASI interval ranging from 3-7 days. The plant height of the maize inbred lines recorded was in the range of $105-120 \mathrm{~cm}$ and the ear placement or ear height varied between 52-66 cm. The genotypes matured between 143 to 155 days, which is very late. No. of kernels per row were from 22 to 34. 100-grain weight ranged from 24 to $32 \mathrm{~g}$. Grain yield of these maize inbred lines per plot ranged from 295 to $361 \mathrm{~g}$ and the protein content recorded was 5 to $7.6 \%$. An 
Z.A.Dar et al. / J. Appl. \& Nat. Sci. 8 (3): 1576 - 1583 (2016)

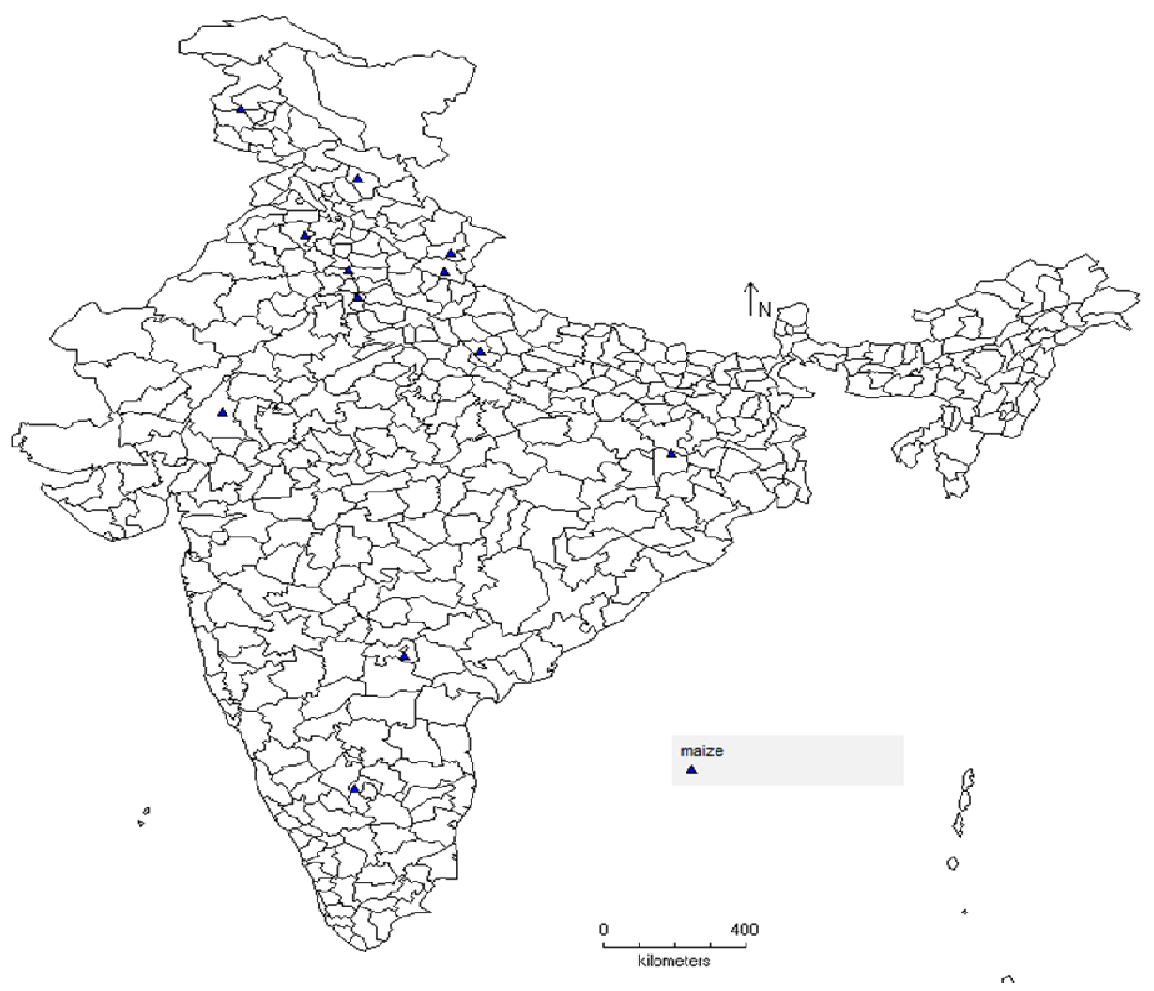

Fig. 1. Source sites of maize inbred lines from India.



A. Plant height

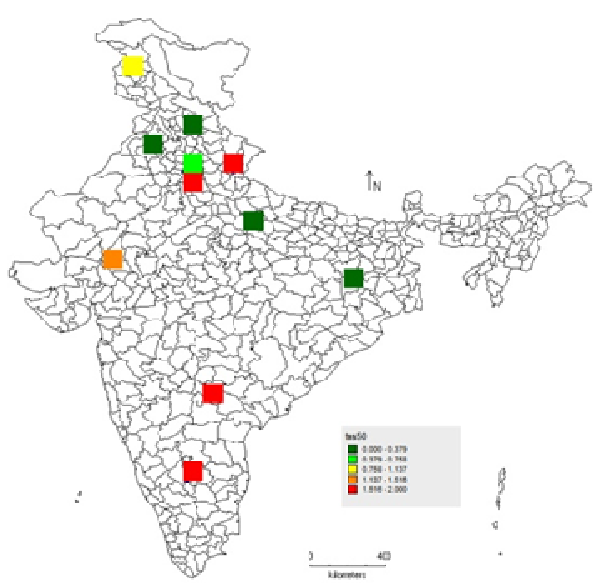

C. Days to $50 \%$ Tasseling

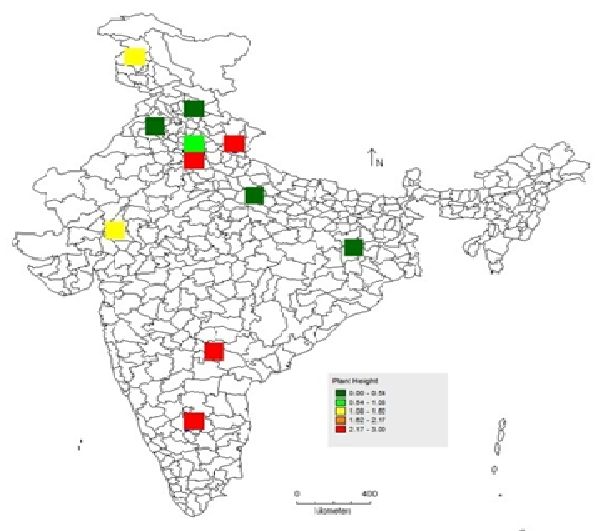

B. Days to $50 \%$ Silking

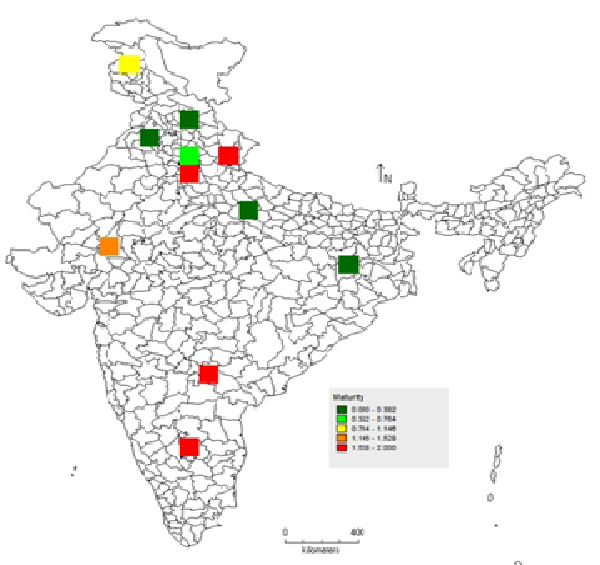

D. Maturity

Fig. 2. Diversity analysis on maize inbred using DIVA-GIS. 


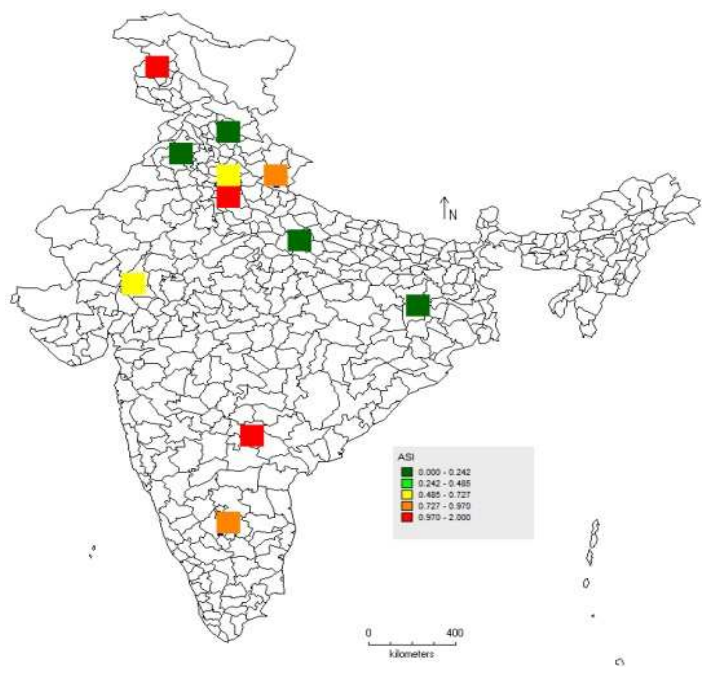

A. ASI

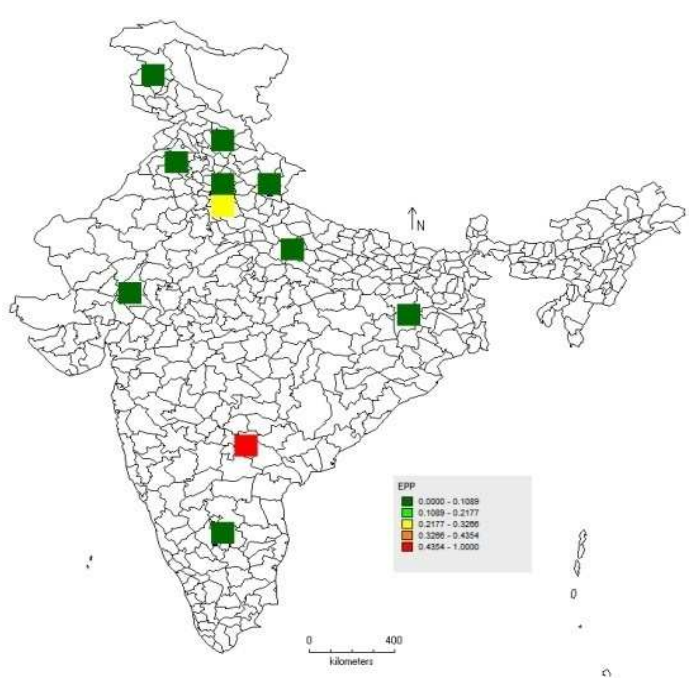

C. EPP

Fig.3. Diversity analysis on maize inbred using DIVA-GIS.

understanding of diversity among elite breeding materials has a significant impact on the improvement of maize crop (Hallauer et al., 1988). Cairns et al (2013) perceived the importance of Geographic information systems (GIS) in targeting breeding programs by predicting regions of vulnerability, targeting germplasm movement and identifying future climates for agricultural production environments. The diversity of the inbred lines was studied using the DIVA-GIS tool, which enables us in the identification of the diverse sources and help in the identification of the possible regions or areas from we can further source our inbreds to used in the crop improvement using the single cross hybrid technology. Geographical Information System has been a valuable tool in natural resources management in India viz., watershed management, land use planning etc. DIVA-GIS, a Geographic Infor-

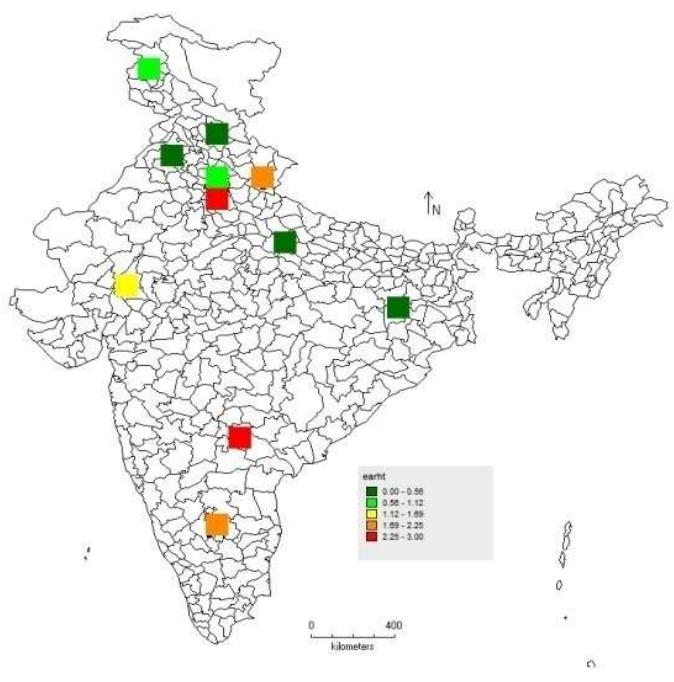

B. Ear Height

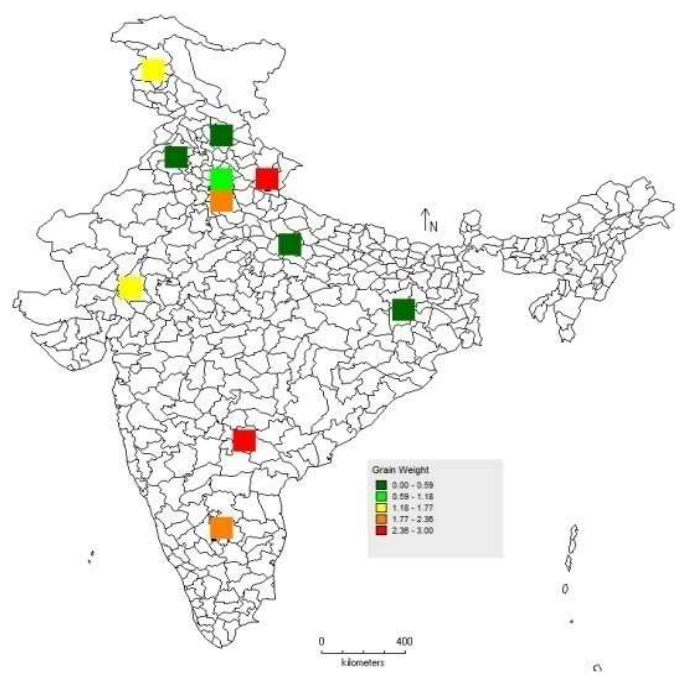

D. Grain weight

mation System (GIS) which is designed to assist the plant genetic resources and biodiversity communities to map the range of distribution of species (Hijmans et al., 2000). However, it is less used for plant genetic resources management in India. DIVA-GIS enable us to understand and comprehend the distribution of diversity on the geographical scale. The source sites of maize inbred lines from India are presented in Fig. 1.

Grid maps generated for diversity analysis of the eleven quantitative traits (Table-1) in maize inbred lines viz., plant height, days to silking, days to tasseling, ASI, days to maturity, ear height, EPP, grain weight, grain yield, Kernel row and protein content (Figs. 2A, B, C, D; 3A, B, C, D; 4A, B, C respectively), indicated that diverse maize inbred for all these traits can be sourced from North and South India. These inbred lines which might have been derived 


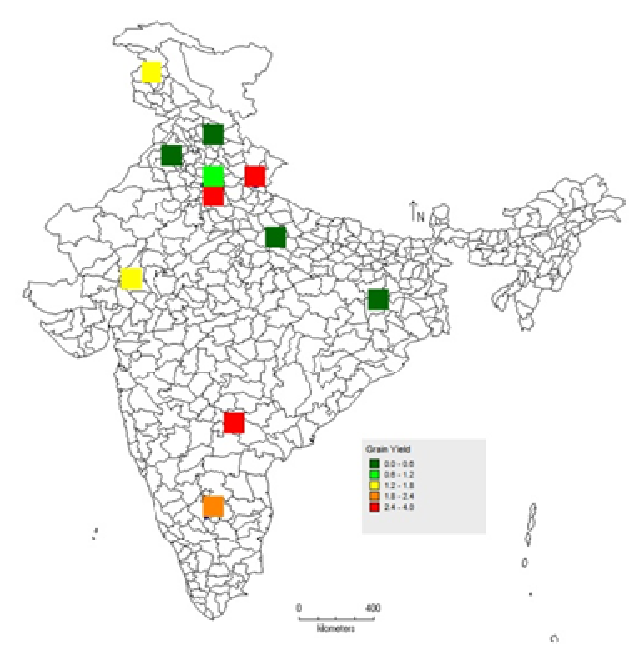

A. Grain yield

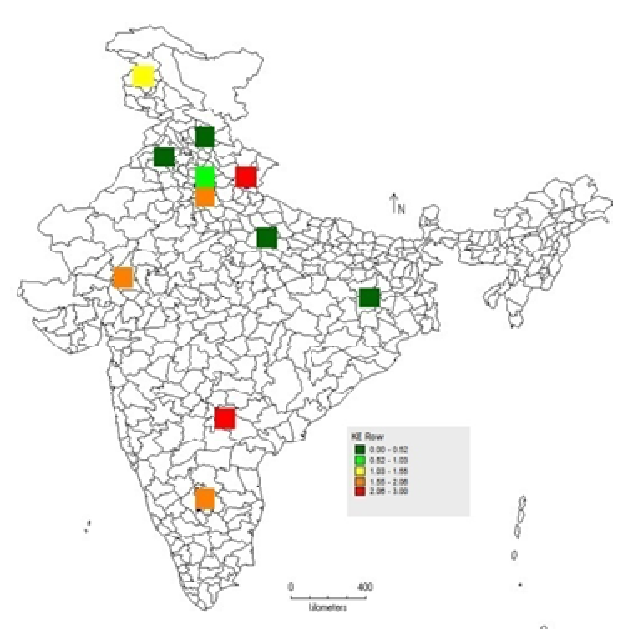

B. K/Row

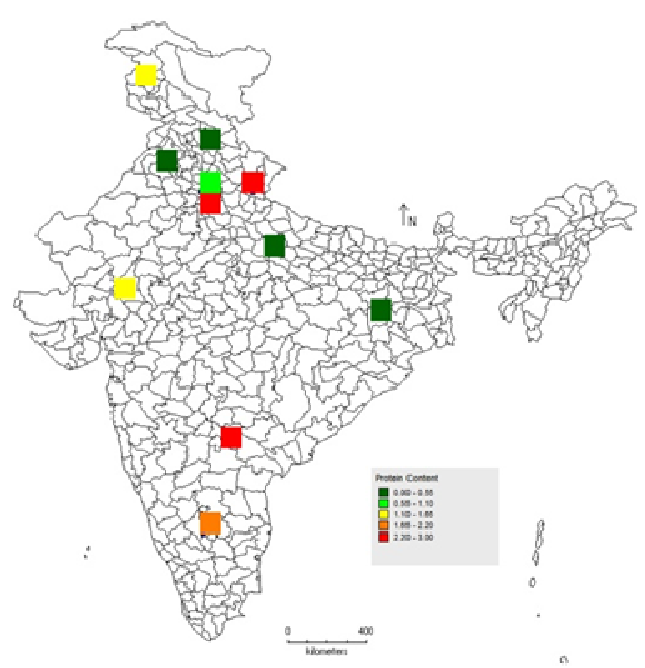

\section{Protein content}

Fig.4. Diversity analysis on maize inbred using DIVA-GIS. through various means viz. selections from landraces, exotic sources, hybrids etc. have been made available to the specific ecosystems based on the needs and adaptability of the local farmers and/or ecosystems. The need for such monitoring of the patterns of change both at the spatial and temporal level have been identified as priority area and key challenge for international community (Prasanna, 2012).

Colours of the grids are indicative of the extent of diversity in the maize inbred lines. High Shannon diversity index with maximum range of 2.17-3.0, 2.25-3.0, 2.36-3.0, 2.4-4.0, 2.0-3.0, and 2.2-3.0 have been recorded for the traits plant height, ear height, grain weight, grain yield, Kernel row and protein content respectively. This shows us the highly responsive traits to ecosystem. However, inbred lines were found to be diverse for all the traits except for EPP and they have been sourced from Northern and Southern parts of India while for EPP which has recorded less diversity index range of 0.4-1.0 is sourced from South India. Interestingly, less diverse inbred lines for all the eleven quantitative traits have been sourced from Indogangetic plains as indicated in diversity grid maps. Maximum diversity indices recorded for ASI, days to silking, days to tasseling, maturity are in the range of $0.97-2.0,1.528-2.0,1.516-2.0$ and 1.528-2.0 respectively. Grid maps further indicated that diverse inbred lines for the trait ASI had been sourced from Northern most regions also.

Similar observations were made in black gram (Babu et al., 2010), linseed (Sivaraj et al., 2009, 2012) and onion (Kamala et al., 2011) germplasm. Interestingly days to $50 \%$ tasseling, days to $50 \%$ silking and days to maturity have generated similar maps (Fig. 2B,C \& D) pointing towards a trend in the genotypes-late flowering lines taking more time to mature. This trend may be under threat under the climate change conditions when the increase in temperatures may hasten up the maturity of the late tasseling and silking lines. Also, ASI and ear height (Fig. 3A \& B) data have generated similar maps, which appears to be not of much significance. Similarly, not much can be read into the same maps generated for grain yield and protein content (Fig. 4 A \& C). The analyses indicate that traitspecific diverse accessions of inbred lines occur in various regions of India. The diversity pattern of maize inbred lines (grid maps) revealed that a good amount of diversity existed for all the 11 traits studied except for ears per plant. DIVA-GIS mapping may be effectively used diversity analysis, identifying gaps in collection, distribution pattern and for developing new strategies for conservation, particularly in the wake of recent international developments related to food and nutritional security. GIS mapping has been successfully used in assessing biodiversity and in identifying areas of high diversity in Phaseolus bean (Jones et al., 1997); wild potatoes (Hijmans et al., 2000, 2003); 
Z.A.Dar et al. / J. Appl. \& Nat. Sci. 8 (3): 1576 - 1583 (2016)

Table 1. Data (Pooled) of the inbred lines used to generate the grid maps using DIVA-GIS software.

\begin{tabular}{|c|c|c|c|c|c|c|c|c|c|c|c|}
\hline Inbred line & DT & DS & ASI & PH & EH & DM & EPP & KR & 100-Gw & GY & $\mathrm{Pr}$ \\
\hline CM-129 & 76 & 80 & 4 & 118.7 & 65.6 & 145 & 1 & 32.2 & 30.78 & 359.7 & 6.73 \\
\hline CM-135 & 80 & 85 & 5 & 108.6 & 55 & 150 & 1 & 26.4 & 26.17 & 332.3 & 6.17 \\
\hline CML-72 & 81 & 86 & 5 & 105.4 & 53.8 & 151 & 1 & 28.2 & 24.33 & 324.8 & 5.98 \\
\hline CML-128 & 80 & 85 & 5 & 109.8 & 56.8 & 150 & 1 & 24.8 & 28.24 & 317.8 & 5.76 \\
\hline CML-139 & 82 & 87 & 5 & 112.6 & 59.2 & 152 & 1 & 24.6 & 27.26 & 326.6 & 5.35 \\
\hline CML-334 & 84 & 90 & 6 & 113.2 & 60.8 & 155 & 1 & 28.8 & 26.88 & 302.8 & 5.89 \\
\hline CML-414 & 82 & 88 & 6 & 111 & 58.2 & 153 & 1 & 22 & 24.78 & 312.1 & 5.41 \\
\hline CML-491 & 80 & 85 & 5 & 114.6 & 61.9 & 150 & 1 & 26.6 & 25.03 & 334.5 & 6.21 \\
\hline CML-502 & 78 & 83 & 5 & 111.5 & 58.2 & 148 & 1 & 28.4 & 28.66 & 304.4 & 5.49 \\
\hline HK-1040-4 & 84 & 90 & 6 & 113 & 60.2 & 155 & 1 & 24.4 & 28.88 & 305.6 & 6.22 \\
\hline HKI-586 & 82 & 86 & 4 & 114.7 & 61.6 & 151 & 1 & 24.8 & 27.2 & 323.8 & 6.23 \\
\hline KDM-323A & 84 & 89 & 5 & 113.2 & 60.6 & 154 & 1 & 28.8 & 25.24 & 305.2 & 5.95 \\
\hline KDM-331 & 74 & 78 & 4 & 117.2 & 64.7 & 143 & 1 & 30.8 & 29.87 & 360.8 & 7.29 \\
\hline KDM-332A & 80 & 85 & 5 & 110.5 & 57.2 & 150 & 1 & 26.2 & 28.67 & 314.9 & 5.73 \\
\hline KDM-332B & 78 & 83 & 5 & 114 & 61.6 & 148 & 1 & 26.6 & 28.94 & 336.5 & 5.33 \\
\hline KDM-339 & 84 & 90 & 6 & 112.6 & 59.6 & 155 & 1 & 26.4 & 27.06 & 328.4 & 5.49 \\
\hline KDM-340A & 82 & 86 & 4 & 113.2 & 60.5 & 151 & 1 & 28.2 & 26.6 & 305.2 & 6.22 \\
\hline KDM-343A & 76 & 80 & 4 & 116.6 & 62.5 & 145 & 1 & 32.6 & 29.67 & 359.9 & 7.65 \\
\hline KDM-344 & 80 & 85 & 5 & 114.7 & 60.3 & 150 & 1 & 28.4 & 28.94 & 311.1 & 5.33 \\
\hline KDM-347 & 81 & 86 & 5 & 105.3 & 53.8 & 151 & 1 & 24.4 & 24.78 & 299.4 & 6.12 \\
\hline KDM-351 & 73 & 78 & 5 & 119.6 & 66.5 & 143 & 1 & 30.8 & 30.56 & 360.3 & 6.89 \\
\hline KDM-356A & 80 & 85 & 5 & 111.6 & 58.6 & 150 & 1 & 24.2 & 27.12 & 324.7 & 6.87 \\
\hline KDM-361A & 78 & 83 & 5 & 114 & 61.3 & 148 & 1 & 26 & 26.52 & 314.4 & 5.35 \\
\hline KDM-362A & 84 & 90 & 6 & 111.5 & 58.6 & 155 & 1 & 24.4 & 24.83 & 325.2 & 5.89 \\
\hline KDM-362B & 76 & 79 & 3 & 118.2 & 65.8 & 144 & 1.5 & 33.8 & 31.67 & 359.1 & 7.07 \\
\hline KDM-370 & 82 & 86 & 4 & 112.4 & 58.8 & 151 & 1 & 24.4 & 27.2 & 302.8 & 5.65 \\
\hline KDM-372 & 80 & 85 & 5 & 114.7 & 62.5 & 150 & 1 & 28.8 & 26.08 & 312.1 & 6.14 \\
\hline KDM-375 & 78 & 83 & 5 & 108.6 & 55.9 & 148 & 1 & 26.2 & 24.8 & 334.5 & 5.95 \\
\hline KDM-381A & 84 & 90 & 6 & 105.4 & 53.8 & 155 & 1 & 26.6 & 25.06 & 304.4 & 5.73 \\
\hline KDM-381B & 82 & 86 & 4 & 108.6 & 55 & 151 & 1 & 26.4 & 28.56 & 301.5 & 5.33 \\
\hline KDM-382A & 76 & 80 & 4 & 117.4 & 64.8 & 145 & 1 & 33.4 & 30.66 & 358.9 & 7.24 \\
\hline KDM-400 & 84 & 89 & 5 & 112.6 & 59.7 & 154 & 1 & 28.8 & 26.1 & 304.4 & 5.95 \\
\hline KDM-402 & 74 & 78 & 4 & 116.8 & 63.8 & 143 & 1 & 31.8 & 30.45 & 360.1 & 7.24 \\
\hline KDM-404 & 80 & 85 & 5 & 113.2 & 60.1 & 150 & 1 & 26.2 & 24.12 & 325.6 & 5.73 \\
\hline KDM-415 & 78 & 83 & 5 & 110.5 & 58.6 & 148 & 1 & 26.6 & 28.34 & 313.8 & 5.35 \\
\hline KDM-429 & 82 & 86 & 4 & 108.7 & 53.5 & 151 & 1 & 26.6 & 26.52 & 324.2 & 5.41 \\
\hline KDM-431 & 81 & 86 & 5 & 107.5 & 52.4 & 151 & 1 & 28.4 & 24.83 & 323.6 & 6.21 \\
\hline KDM-439 & 80 & 85 & 5 & 113.5 & 60.4 & 150 & 1 & 24.4 & 25.23 & 328.2 & 5.49 \\
\hline KDM-440 & 82 & 87 & 5 & 114.6 & 61.3 & 152 & 1 & 24.8 & 28.39 & 317.8 & 6.22 \\
\hline KDM-443 & 84 & 90 & 6 & 111.5 & 57.5 & 155 & 1 & 28.2 & 28.08 & 326.6 & 6.23 \\
\hline KDM-445A & 76 & 80 & 4 & 117.2 & 64.1 & 145 & 1 & 30.6 & 29.98 & 360.9 & 7.05 \\
\hline KDM-456A & 78 & 83 & 5 & 114 & 59.7 & 148 & 1 & 28.4 & 28.66 & 317.8 & 5.89 \\
\hline KDM-463 & 84 & 90 & 6 & 111.5 & 58.6 & 155 & 1 & 24.4 & 28.88 & 326.6 & 6.92 \\
\hline KDM-716 & 82 & 86 & 4 & 113 & 59.7 & 151 & 1 & 24.8 & 27.2 & 302.8 & 6.2 \\
\hline KDM-717 & 81 & 86 & 5 & 114.7 & 60.4 & 151 & 1 & 28.2 & 26.08 & 312.1 & 5.65 \\
\hline KDM-720 & 76 & 81 & 5 & 109.8 & 55.7 & 146 & 1 & 24.4 & 24.87 & 334.5 & 6.14 \\
\hline KDM-724 & 73 & 78 & 5 & 116 & 63.3 & 143 & 1 & 33.7 & 31.19 & 361.2 & 7.22 \\
\hline KDM-741 & 80 & 85 & 5 & 113.5 & 60.4 & 150 & 1 & 26.4 & 24.8 & 307.7 & 5.03 \\
\hline KDM-892A & 82 & 87 & 5 & 114.6 & 61.3 & 152 & 1 & 28.2 & 25.06 & 294.8 & 5.25 \\
\hline KDM-895A & 82 & 89 & 7 & 112.4 & 58.8 & 154 & 0.75 & 24.8 & 24.78 & 325.2 & 5.11 \\
\hline KDM-899A & 80 & 85 & 5 & 114.7 & 62.5 & 150 & 1 & 28.2 & 25.03 & 324.8 & 6.51 \\
\hline KDM-909A & 76 & 79 & 3 & 116.6 & 62.5 & 144 & 1.5 & 32.6 & 31.25 & 360.9 & 6.89 \\
\hline KDM-911A & 76 & 81 & 5 & 113.2 & 60.1 & 146 & 1 & 24.4 & 25.23 & 304.4 & 6.23 \\
\hline KDM-912A & 84 & 89 & 5 & 110.5 & 58.6 & 154 & 1 & 28.8 & 28.39 & 305.6 & 5.65 \\
\hline KDM-913A & 80 & 85 & 5 & 113.5 & 60 & 150 & 1 & 26.2 & 28.08 & 323.8 & 6.14 \\
\hline KDM-914A & 78 & 83 & 5 & 108.7 & 53.5 & 148 & 1 & 26.6 & 27.2 & 311.6 & 5.95 \\
\hline KDM-915 & 84 & 90 & 6 & 107.5 & 52.4 & 155 & 1 & 26.6 & 26.08 & 324.2 & 5.13 \\
\hline KDM-916A & 76 & 79 & 3 & 116.8 & 63.3 & 144 & 1.5 & 32.4 & 28.03 & 359.6 & 6.56 \\
\hline
\end{tabular}


Contd.......

\begin{tabular}{llllllllllll}
\hline KDM-917A & 78 & 83 & 5 & 113 & 59.7 & 148 & 1 & 28.4 & 28.34 & 326.6 & 5.65 \\
KDM-918A & 84 & 90 & 6 & 114.7 & 60.4 & 155 & 1 & 24.4 & 27.12 & 302.8 & 6.71 \\
KDM-921A & 82 & 86 & 4 & 109.8 & 55.7 & 151 & 1 & 24.8 & 26.52 & 312.1 & 5.5 \\
KDM-924A & 81 & 86 & 5 & 112.6 & 59.7 & 151 & 1 & 28.2 & 24.83 & 334.5 & 6.22 \\
KDM-926B & 75 & 79 & 4 & 117.2 & 64.7 & 144 & 1 & 31.8 & 29.66 & 359.1 & 6.89 \\
KDM-930A & 80 & 85 & 5 & 111.5 & 58.6 & 150 & 1 & 26.6 & 24.12 & 317.8 & 5.29 \\
KDM-932A & 82 & 87 & 5 & 113.2 & 60.4 & 152 & 1 & 22.8 & 25.23 & 296.2 & 6.52 \\
KDM-935A & 76 & 79 & 3 & 117.7 & 64.7 & 144 & 1.5 & 32.2 & 30.78 & 361.5 & 7.54 \\
KDM-940A & 81 & 86 & 5 & 113.2 & 60.8 & 151 & 1 & 24.6 & 24.54 & 305.6 & 6.43 \\
KDM-940B & 76 & 81 & 5 & 111 & 58.2 & 146 & 1 & 26.4 & 25.65 & 311.8 & 6.74 \\
KDM-957 & 80 & 85 & 5 & 108.6 & 55.4 & 150 & 1 & 24.4 & 25.76 & 322.7 & 6.21 \\
KDM-958 & 76 & 80 & 4 & 116.7 & 63.4 & 145 & 1 & 33.8 & 29.67 & 358.9 & 6.94 \\
KDM-961 & 82 & 86 & 4 & 113.2 & 60.5 & 151 & 1 & 28.2 & 26.6 & 305.2 & 6.22 \\
KDM-969 & 81 & 86 & 5 & 111.6 & 58.6 & 151 & 1 & 26.8 & 24.38 & 297.8 & 6.23 \\
KDM-1016 & 80 & 85 & 5 & 114 & 61.3 & 150 & 1 & 24.8 & 25.11 & 312.1 & 5.65 \\
KDM-1051 & 82 & 86 & 4 & 112.5 & 59.7 & 151 & 1 & 24.8 & 25.23 & 301.8 & 5.41 \\
KDM-3001 & 84 & 90 & 6 & 113.2 & 60.8 & 155 & 1 & 26.8 & 26.08 & 305.6 & 5.65 \\
KDM-3006 & 78 & 83 & 5 & 111 & 58.2 & 148 & 1 & 24.8 & 27.12 & 321.8 & 6.14 \\
KDM-3007 & 84 & 90 & 6 & 114.6 & 61.9 & 155 & 1 & 26.2 & 26.52 & 318.6 & 5.95 \\
KDM-3008 & 82 & 86 & 4 & 111.5 & 58.2 & 151 & 1 & 26.4 & 24.83 & 328.2 & 5.13 \\
KDM-914 & 81 & 86 & 5 & 113 & 60.2 & 151 & 1 & 24.2 & 25.23 & 317.8 & 5.03 \\
\hline
\end{tabular}

horse gram (Sunil et al., 2008); Jatropha curcas (Sunil et al., 2009); linseed (Sivaraj et al., 2009); black gram (Babu Abraham et al., 2010); Canavalia fatty acids (Sivaraj et al., 2010); onion (Kamala Venkateswaran et al., 2011); medicinal plants (Varaprasad et al., 2007), and agro biodiversity (Varaprasad et al., 2008). However, the present study is a maiden attempt towards the study of genetic diversity of maize inbred lines. Molecular markers have been used to assess the genetic diversity in maize inbred lines in recent past (Li et al., 2002; Liu et al., 2003; Jambrovic et al.,2008; Yadav and Singh, 2010).

The targeted ecosystem is known for cultivating early and extra early duration genotypes, however sourced inbreds have recorded duration of 143-155 days to maturity which falls under the late maturity group per se the set of inbred lines may not be useful for the target ecosystem but traits like ASI which have shown a range of 3- 6 (only one genotype recorded 7 days) even in the new ecosystem, which could face similar temperatures and other climatic variables as the sourced inbred lines, in the days to come need to be furthered in the breeding programme as it has been reported that increased temperature are set to shorten the length of the growing cycle, decreasing opportunity to capture more radiation and reducing total $\mathrm{CO} 2$ assimilation, and reducing total biomass and grain yield as suggested by previous studies (Tao \& Zhang, 2011). Tao and Zang (2010) had also suggested testing with such adapted cultivars and to ascertain as to what fraction of the yield variation was contributed by life cycle length compared to other direct effects of temperature on assimilation and grain-set. Howden et al. (2007) have identified that adaptation to climate change will require cross-disciplinary solutions and also Cairns et al. (2013) underscored the urgent need to identify the most vulnerable regions so that the breeding programs are able to deliver improved genotypes to offset poten- tial losses under climate change. Our present study highlights the use of DIVA-GIS tool to be employed in the identification of diverse sources from varied ecosystems which can be used for delivering improved cultivars in general and more so in the light of challenge due to climate change.

\section{Conclusion}

DIVA-GIS is a tool designed to assist the plant genetic resources and biodiversity communities to map the range of species distribution. Grid maps generated for diversity analysis of the eleven quantitative traits in maize inbred lines indicated that diverse maize inbred for all these traits can be sourced from North and South India. Grid colours are indicative of the extent of diversity in the maize inbred lines. High Shannon diversity index with maximum range of 2.17-3.0, 2.25 -3.0, 2.36-3.0, 2.4-4.0, 2.0-3.0, and 2.2-3.0 have been recorded for the traits plant height, ear height, grain weight, grain yield, kernel row and protein content respectively indicating the highly responsive traits to ecosystem. However, inbred lines were found to be diverse for all the traits except for EPP and they have been sourced from Northern and Southern parts of India while for EPP which has recorded less diversity index range of 0.4-1.0 is sourced from South India. Interestingly, less diverse inbred lines for all the eleven quantitative traits have been sourced from Indogangetic plains as indicated in diversity grid maps. Maximum diversity indices recorded for ASI, days to silking, days to tasseling, maturity are in the range of $0.97-2.0,1.528-2.0,1.516-2.0$ and 1.528-2.0 respectively. Hence, DIVA-GIS enabled identification of diverse sources from varied ecosystems which can be used for developing improved lines/ cultivars with greater resilience towards climate change. 


\section{REFERENCES}

Anonymous, 2015. Annual Maize Report, Dryland Agricultural Research Station, SKUAST-K pp-9-10.

Babu, A.V., Kamala, N., Sivaraj, N., Sunil, N., Pandravada, S. R., Vanaja, M. and Varaprasad, K.S. (2010). DIVAGIS approaches for diversity assessment of pod characteristics in black gram (Vigna mungo L. Hepper). Current Sci., 98(5): 616-619.

Cairns, J.E., Sonder, K., Zaidi, P.H., Verhulst, P.N., Mahuku, G., Babu, R., Nair, S.K., Das, B., Govaerts, B., Vinayan, M.T., Rashid, Z., Noor, J.J., Devi, P., Vicente, F. san, and Prasanna, B.M. (2012). Maize production in a changing climate: Impacts, adaptation, and mitigation strategies. Advances in Agronomy 114: 1-65.

Cairns, J.E., Hellin, J., Sonder, K., Araus, J.L., MacRobert, J.F., Thierfelder, C., and Prasanna, B.M. (2013). Adapting maize production to climate change in sub-Saharan Africa. Food Security 5(3): 345-360.

Easterling, W., Aggarwal, P., Batima, P., Brander, K., Erda, L., Howden, M., Kirilenko, A., Morton, J., Soussana, J.F., Schmidhuber, J. and Tubiello, F. (2007). Food Fibre and Forest Products. In Climate Change 2007: Impacts, Adaptation and Vulnerability (Oarry, M.L., Canziani, O.F., Palutikof, J.P., Van der Lindin, P.J., and Hanson, C.E. Eds.). pp 273-313, Cambridge University Press, Cambridge, UK.

Hijmans, R.J., Garret, K.A., Huaman, Z., Zhang, D.P., Schreuder, M. and Bonierbale. (2000). Assessing the geographic representatives of genebank collections:the case of Bolivian wild potatoes. Conservation Biology 14: $1755-1765$.

Hijmans, R.J, Guarino, Cruz, M. and Rojas, E. (2001). Computer tools for spatial analysis of plant genetic resources data. Plant Genetic Resources Newsletter 127: 15-19.

Hallauer, A.R., Russell, W.A. and Lamkey, K.R. (1988). Corn Breeding. In: Corn and Corn Improvement, 3rd edn. Agron Monogr 18, ASA-CSSA-SSSA, Madison, Wisconsin, USA. pp. 469-564.

Hijmans, Robert, J., Mirjam, J., John, B., Bamberg, and David, M.S. (2003). Frost tolerance in wild potato species: Assessing the predictivity of taxonomic, geographic, and ecological factors. Euphytica 130: 47-59.

Howden, S.M., Soussana, J.F., Tubiello, F.N., Chhetri, N., Dunlop, M., and Meinke, H. (2007). Adapting agriculture to climate change. Proceedings of the National Academy of Sciences 104(50): 19691-19696.

Jambrovic, A., Simic, D., Leden, T., Zdunic, Z. and Brkic, I. (2008). Genetic diversity among maize (Zea mays L.) inbred lines in Eastern Croatia. Periodicum Biologorum 110 (3): 251-255.

Jones, P.G., Beebe, S.E., Tohme, J. and Galway, N.W. (1997). The use of geographical information systems in biodiversity exploration and conservation. Biodiversity and Conservation 6: 947-958.

Kamala, V., Gupta, A.J., Sivaraj, N., Pandravada, S.R., Sunil, N., Varaprasad, K.S and Lawande, K.E. (2011). Diversity analysis of onion germplasm collections from north Telangana region of Andhra Pradesh. Indian J. Plant Genet. Resour. 24(2): 163-171.

Li, Y., Du, J., Wang, T., Shi, Y., Song, Y. and Jia, J. (2002). Genetic diversity and relationships among Chinese maize inbred lines revealed by SSR markers. Maydica 47: 93-101.

Liu, K., Goodman, M., Muse, S., Smith, J.S., Buckler, Ed. and Doebley, J. (2003). Genetic structure and diversity among maize inbred lines as inferred from DNA microsatellites. Genetics 165: 2117-2128.

Prasanna, B.M. (2012). Diversity in global maize germplasm: Characterization and utilization. Journal of Biosciences 37(5): 843-855.

Sivaraj, N., Sunil, N., Pandravada, S.R., Kamala, V., Vinod, K., Rao, B.V.S.K, Prasad, R.B.N. and Varaprasad, K.S. (2009). DIVA-GIS approaches for diversity assessment of fatty acid composition in linseed (Linum usitatissimum L.) germplasm collections from peninsular India. Journal of Oilseeds Research. 26: 13-15.

Sivaraj, N., Sunil, N., Pandravada, S.R., Kamala, V., Rao, B.V.S.K., Prasad, R.B.N., Nayar, E.R., Joseph, John, K., Abraham, Z. and Varaprasad, K.S. (2010). Fatty acid composition in seeds of Jack bean [Canavalia ensiformis (L.) DC] and Sword bean [Canavalia gladiata Jacq.) DC] germplasm from South India: A DIVA-GIS analysis. Seed Technology 32(1): 46-53.

Sivaraj, N., Sunil, N., Pandravada, S.R., Kamala, V., Vinod, K, Babu, A., Rao, B.V.S.K., Prasad, R.B.N. and Varaprasad, K.S. (2012). Variability in linseed (Linum usitatissimum) germplasm collections from peninsular India with special reference to seed traits and fatty acid composition. Indian Journal of Agricultural Sciences 82 (2): 102-105.

Sunil, N., Sivaraj, N., Pandravada, S.R., Kamala, V., Raghuram, R.P. and Varaprasad, K.S. (2008). Genetic and geographical divergence in horsegram germplasm from Andhra Pradesh, India. Plant Genetic Resources: Characterization and Utilization 7(1): 84-87.

Sunil, N., Sivaraj, N., Anitha, K., Babu, A., Vinod, K.E., Sudhir, M., Vanaja and Varaprasad, K.S. (2009). Analysis of diversity and distribution of Jatropha curcas L. germplasm using Geographic Information System (DIVA-GIS). Genetic Resources and Crop Evolution 56: 115-119.

Tao, F. and Zhang, Z. (2010). Adaptation of maize production to climate change in North China Plain: Quantify the relative contributions of adaptation options. European Journal of Agronomy 33(2): 103-116.

Tao, F. and Zhang, Z. (2011). Impacts of climate change as a function of global mean temperature: maize productivity and water use in China. Climate Change 105(3/5): 409-432.

Varaprasad, K.S, Sivaraj, N., Mohd, I. and Pareek, S.K. (2007). GIS mapping of selected medicinal plants diversity in the Southeast Coastal Zone for effective collection and conservation. In: Advances in Medicinal Plants (eds. K. Janardhan Reddy, Bir Bahadur, B. Bhadraiah and MLN Rao). Universities Press (India) Private Ltd. pp.69-78.

Varaprasad, K.S., Sivaraj, N., Pandravada, S.R., Kamala, V. and Sunil, N. (2008). GIS mapping of Agrobiodiversity in Andhra Pradesh. Proceedings of Andhra Pradesh Akademi of Sciences. Special Issue on Plant wealth of Andhra Pradesh. pp: 24-33.

Yadav, V.K. and Singh, I.S. (2010). Comparative evaluation of maize inbred lines (Zea mays L.) according to DUS testing using morphological, physiological and molecular markers. Agricultural Sciences 1(3): 131-142. 